\title{
Application of Nanomaterials in Transportation Engineering
}

\author{
Er. Puneet Jain ${ }^{1}$,Auwal Alhassan Musa ${ }^{2}$, Lasmar Garba $^{3}$ \\ Department of Civil Engineering \\ (Assistant Professor, Both is student of M. Tech. Transportation Eng. (Pursuing) \\ Mewar University, Rajasthan, India
}

\begin{abstract}
Civil engineering is one of the vast specializations that required an advanced research to utilize the current trend in nanotechnology especially utilizing eco-friendly nanomaterial for various construction such as roads, building soil stabilizations, and backfill material treatment this is because the current available material might be expensive and hard to obtain at nearby construction sites. the application of nanomaterialsis mostly specifically for improving the strength properties, Durability of already constructed infrastructure, non-concurrent maintenance, and life spanning increment. not the addition of quantity to the current existing construction material available in practice. as Nanotechnology is focused on materials in nanoscale while civil engineering infrastructure focused on the macro scale.Furthermore, there is challenge of increase in traffic due sudden rise of human population in most of the developed cities in the world. hence, the need of high performance, durable material is needed to cater for this challenge in pavement construction. Though most application of nanomaterials in pavement is still in its initial stage. But nevertheless, there is much to prevail in using such materials for road construction. Concrete and asphalt pavements are widely used throughout the world, however; they are expensive materials. Applying nanotechnology innovations with these materials can improve performance and increase durability, which in the long run can lead to a cost-effective solution. Nonetheless nanotechnology needs special attention regarding its application, toxic nature to health environment and groundwater pollution
\end{abstract}

Keywords: Nanotechnology, nanomaterials, pavements, strength, heath

\section{INTRODUCTION}

Nanotechnology is a current phase of technology that deals with the materials in smaller sizes (nanometers), therefore any materials that is in which its dimension is in nanometers i.e. billionth in meter is known as nanomaterials. There are different forms and types of nanotechnology, some are eco-friendlycausinglittle or no negative impact toenvironmental, social and health damage to the habitantsupon exposure while some are toxic in nature, therefore the nature of civil engineering activities deal with environmental and public exposure project needs to utilize the eco-friendly type of nanomaterials. Though most of the materials properties changes when they reached nano stage.Also,civil engineering construction is too challenge full as it needs material with higher strength and lower density but unfortunately most of the material available for civil engineering construction are of higher density and strength.therefore,nanomaterials will provide a means in which such material can be modified to have lower density and least maintain the initial strength (Thostenson et. Al., 2001). its universally accepted that nanomaterial have larger surface area per unit volumewhich results in both early and higher strength due to rapid hydration and which is very vital in construction activities (Neville, 2001).

The normal conventional materials for road construction are basically soil and aggregates, bitumen which sometimes modifies with certain admixture in order to improve its performance. Butunfortunately,concurrent problems keep existing such as incompatibility between some aggregates and bituminous materials, deterioration due environmental changes, susceptibility of large grain in water and temperature sensitivity of binders. (Steyn, 2009).Thus, in cooperating nanomaterials in road construction will help in improving the existing properties of pavement such as resistance in temperature variation, fatigue minimization, crack healing, surface rutting protection (Bartos, et al., 2004).

\subsection{SOME NANO MATERIALS FOR CIVIL ENGINEERING INFRASTRUCTURAL CONSTRUCTION}

\subsection{Carbon Nano Tubes (CTNs)}

Considering the current available construction materials carbon nanotubes happens to be the strongest material proved from its properties, which haselastic modulusof 1.8 tetra pascal, a tensile strength of $63 \mathrm{GPa}$ and a density of $1.4 \mathrm{~g} / \mathrm{cm}^{3}$. Thus, carbon nanotube has strength 120 times that of steel and is a much lighter material as found by (Dresselhaus, 2001). Paint and binders adultered with carbon nano tubes happens to have a high resistibility they usually applied in ships, bridges and boat surface to have a durable and weather changes resistance which will last longer (forth bridge nano technology, 2001). Constructions of state-of-the-art bridges with large suspended cables made up of steel wire have now being replaced with CTNs materials that has smaller sizes and high strength compared to that conventional steel materials. (Makar and Beaudoin, 2003).a little addition not more than $0.05 \%$ of CTNs in concrete can be able to fill pores present in which makes it more impermeable to concrete degradingagents such water and salt, lower density and thermal conductivity, increase its compressive strength, and provide homogeneous pore wall structure, but the distribution of CTNs particles in concrete matrix happens to be much difficult and may lead to the losses of their intended application this is due higher surface area and existence of Vander wall forces in the 
CTNs as it was studied by (Ferro et. al, 2011). But (Gdoutos et al, 2010) proposed that the distribution of CTNs particles can be done successfully by the use of ultrasonic energy. Another method of dispersion CTNs was proposed by (Nasibulin et al., 2011) where they employed the use of cement hybrid material or $\mathrm{CMH}$. With was confirmed to have twice the compressive strength, and 40 times the electrical conductivity of the hardened paste without CNTs.

\subsection{Carbon Nano Fibers (CNFs)}

The closely other nanomaterial to the CTNS is carbon nano fibers CNFs which it made upof grapheme (the thinnest and strongest construction material ever invented, consisting of only a mono layer of carbon atoms). In grapheme, the atoms are arranged in a hexagonal pattern layers arranged in stacked of cones, cup or plates. And then wrapped in perfect layer to form cylinders is termed as carbon nano fibers.(Jacobsen, et.al., 1995). Even though both CTNs and CNFs performed the same function on most of the civil engineering construction but CNFs is regarded as the best option prior to the CTNs this is because the stacked edge structure can produce large surface area they can be produced easily and have comparable lesser cost to CNTs. (Coleman, et. al., 2006). The idea of self-heating concrete proposed andphysio-finite element model was prepared to assess the performance of the proposed system by (Chang et, el., 2009) Have been accepted with thecooperatingCNFs as it has high electric conductivity, therefore using it in the concrete to neutralize the effect of using the deicing salt in the snowedregions of the world where salt deicing system is used to melt the ice on the road which causes the reinforcement corrosion.

\subsection{Titanium Oxide (Nano Titania)}

As the names implies its non-synthetized oxide of titanium with chemical symbol of $\mathrm{TiO}_{2}$, its excellent performance in resisting the ultraviolent radiation gave it an opportunity to be used in paints and coatings for providing whiteness, brightness and opacity (Quagliarini., 2012). Also, its stability, resistance to corrosion and possession of photocatalytic characteristicsmakes it to bean excellent agent to be used in glass of windows for the production of self-cleaning surface. The photocatalytic properties of titanium oxide also give birth to the Photocatalytic concrete in 2007 from Italian cement-based company now its produced in commercial scale. But photocatalysis action required UV radiation to be activated and its uses for killing bacteria (Sunada et. el., 1998).

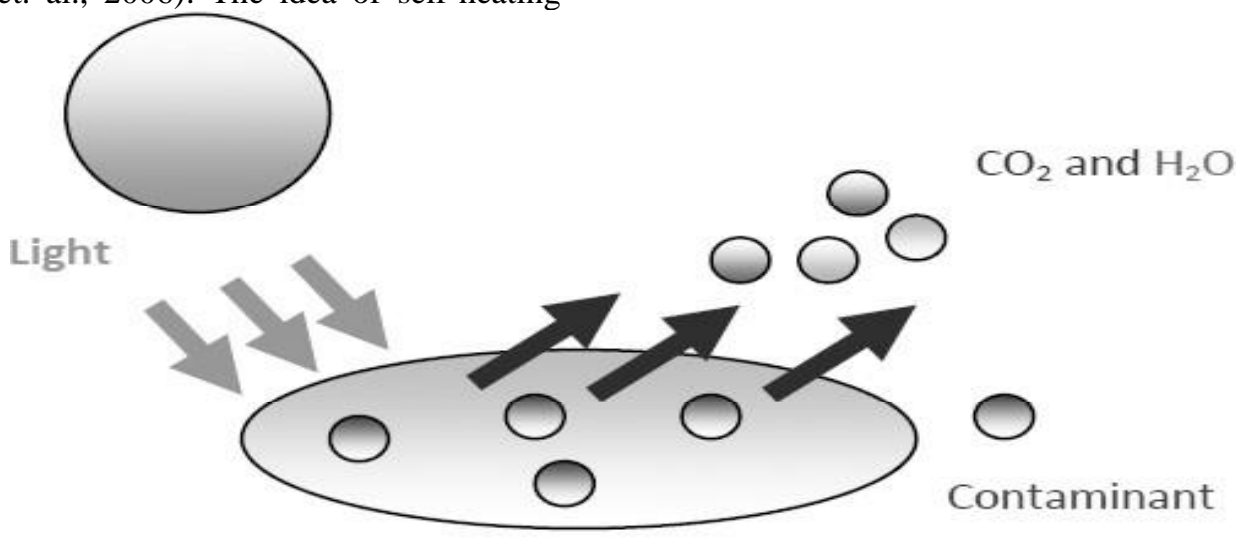

Nano Titania surface

Figure 1.0 Mechanism of nano titania photocatalysis

\subsection{Nano Additives for Concrete}

The emergence of Viscosity Enhancers Reducing Diffusion in Concrete Technology (VERDICT) from National
Institute of Standards and Technology (NIST) USA was successful in reducing the effect of corrosion in steel reinforced within the concrete (Khitab, 2005). Road Surface

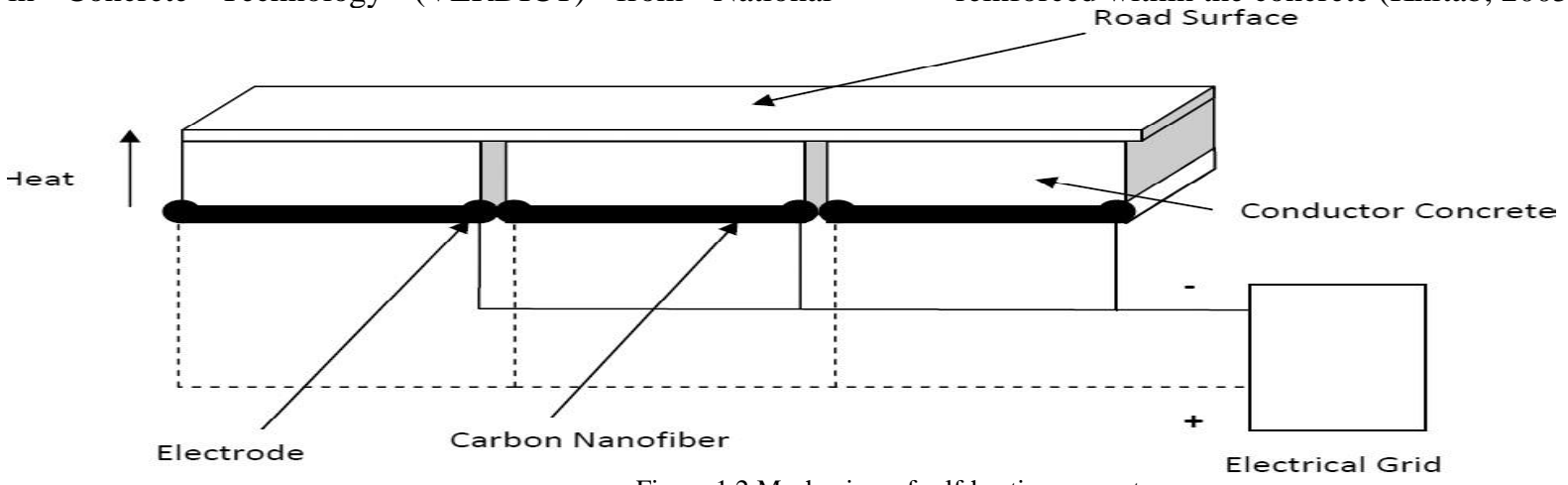

Figure 1.2:Mechanism of self-heating concrete 


\subsection{Nano-Layered Oils in Fibers Reinforced Concrete}

Fiber-reinforced is a type of concrete in which short discrete of synthetic or natural fibers are incorporated. The important fibers used are steel, polypropylene, glass and carbon but Engineered Cementitious Composites (ECC) is a special type of fiber reinforced concrete in which nanoslicked fibers are used which was invented by Dr. Victor Lee of the university of Michigan in USA. Conventional concrete is highly rigid and brittle and has a strain capacity of only $0.1 \%$. therefore, the emergence of ECC is advantageous which gave birth to production of concrete with strain capacity of up to $3 \%$. Which has been claimed to bendable like a metal $(\mathrm{Li}, 2003)$.

\subsection{Nano Silica}

nano silica particles will be more effective if used in lieu of micro silica fumes. Though micro silica fumes are added in concrete to fill in the voids, decrease the concrete alkalinity, and increases its resistance against the chemical attack. Different research groups during the past decade added nano silica particles in concrete and published their experimental data

\subsection{Zycosil}

Zycosil is new nanomaterial generated of nanotechnology, which has been developed for waterproofing and has UV resistance, thermal resistance, and an ability to withstand the wind erosion due to its nano-size penetrative power and its Eco-Friendly abilities. Also,it has some common features such as Permanent water repellent layer on all types of soils, aggregates and other road construction materials. An unending critical subsurface drainage problem in road making and repairs can be made by usingZycosil reactive bonding ability with the aggregates and asphalt helps to eliminate stripping of aggregates to a great extentalso research shows that Zycosil In subgrade, are Maintaining CBR value, Reduction of Soil Plasticity, Maintaining Breathability Used in stone base course,In surface layers. Nonetheless Zycosil has some limitations thus Adverse effects of the solvent used- ethylene glycol, more effective on pre-existing cracks than cracks which occur after the application. 4) It cannot be applied if: $\square$ its less effective in Ambient temperature is below $10^{\circ} \mathrm{C}$ or above $50^{\circ} \mathrm{C}$, expectationof Rain within 2 hours after it was applied, expecting Precipitation to occur within 24 hours prior to application, High winds or other conditions prevent proper application and overspray that may have an adverse effect on surrounding materials. (Priya1, et, al., 2017)

Table 1.0 Some Type of Nanomaterials and Their Area of Application

\begin{tabular}{|l|l|l|}
\hline \multicolumn{1}{|c|}{ S/No } & \multicolumn{1}{|c|}{ NANOPARTICLES } & \multicolumn{1}{c|}{ APPLICATION AREAS } \\
\hline 1 & Nano-silica (SiO2) & $\begin{array}{l}\text { Replaces part of the cement to densify the concrete and gain early strength, } \\
\text { Improving pavement surface characteristics }\end{array}$ \\
\hline 2 & Micro silica (silica fume) & Increase compressive strength and flexural strength in concrete \\
\hline 3 & $\begin{array}{l}\text { Carbon nanotubes (CNTs) } \\
\text { And Carbon nano fibers (CNFs) }\end{array}$ & $\begin{array}{l}\text { Increase compressive strength and flexural strength in concrete, } \\
\text { It can be utilized self-sensing concrete formonitoring the structuralconditions. }\end{array}$ \\
\hline 4 & Nano phosphorus & Improving road visibility \\
\hline 5 & Nano Tio 2 & Self-cleaning of concrete pavement \\
\hline 6 & Polymer fiber matrix using nano silica & Self-Structural Health Monitoring system in Repairs \& Rehabilitation \\
\hline 7 & $\begin{array}{l}\text { high performance steel Using copper } \\
\text { nanoparticles }\end{array}$ & In bridges for corrosion resistance \& better weld ability \\
\hline 8 & Nanotechnology enabled sensors & $\begin{array}{l}\text { To monitor and control temperature, moisture, smoke, noise, stresses, vibrations, cracks and } \\
\text { corrosion }\end{array}$ \\
\hline
\end{tabular}

(Darshan and Mishra, 2017)

\subsection{APPLICATION OF NANOTECHNOLOGY IN CONCRETE PAVEMENTS}

\subsection{Self-Healing Materials}

Most of the work about automatic healing cracks in pavement as still on its infancy stage but some polymers have been in exitance which has such healing ability to crack in rigid pavement. The process is accomplished by incorporating a microencapsulated healing agent and a catalytic chemical trigger within an epoxy matrix of the concrete (Liu, 2009). the initial work on the self-healing ability was performed by (Transportation Research Board, 2012) and the work utilizes cementitious composites using microcapsules (PSMs) with oil and silica gel. In which it was dispersed in fresh mortar incorporated with carbon nano fibers and silica fumes, the result shows that it heals the at least artificially made microcracks.

\subsection{Crack-Healing Materials}

The exceptional properties such as high stiffness, resistance to weather and environmental of carbon nano tubes (CNTs) which resulted from high aspect ratio (ability to be distributed on a much finer scale than commonly used micro reinforcing fibers.), small size, low density, and unique physical and chemical properties make it most suitable nanomaterial for reinforcement. (Plaisted et, al., 2003). CNTs also resist high impact of external load having very High values of elasticity, therefore interfacial attraction between the CNTs and cement hydrates produce high bond strength, which makes the CNTs to act as barriers to the cracks and voids which lead to mechanic of tensional load transfer easily (Kuennen, 2004).

\subsection{Self-cleaning materials}

As it was deeply discussed about the properties of titanium oxide in the previous section. It can be used to activated photocatalytic process. Therefore, when the titanium oxides are used incorporated with concrete it provides a self- cleaning surfaces and gradually reduce pollution cause by air (Camden, 2007). Another research conducted by 
(Hassan, 2009), on impact assessment of titanium oxide on concrete pavements it was found that titanium oxide is very strong photocatalyst agent and hydrophilic agent as well capable of neutralizing any organic substance that touches it when exposed to ultraviolent radiation when thevapor water is presence and as well provides self-cleaning surface to which its applied.

\subsection{Shape memory alloy (SMA) material}

Uneven joints due to differential settlement are mainly occurred at bridge ends, a heavy load or cause large impact on the pavement. Therefore, deterioration of both bridge, automobile damage, prone to accident, other pavement failure such as pavement topping separation from its subgrade. And other intermediate layers, fatigue proper implementation of the SMA nanomaterials will give a remarkable result in solving such problems.

\subsection{APPLICATION OF NANOTECHNOLOGY IN ASPHALT PAVEMENTS}

\subsection{Nanoclays materials}

Due to its recent emergences still, little attention was given to the application of nanomaterials from engineers particularly civil and transportation engineers. But appropriate implementation of nanomaterials such as nano clay (montmorillonite and layered silicates) modified in polymer matrix within pavement will result in durable, weather and skid resistance surface for airport, highways and ports. (Partl, 2004) though some research has to be done before using nanoclays in large scale as suggested by ((Partl, 2004) in order to assess its low-temperature, cracking performance fatigue resistance, but with current research result it was found to have effective toughness increases as the addition of nanoclays materials increases.

\subsection{Saline and Acrylic Co-Polymer for Pavement Construction in Water Logged Area}

Water logging area having a higher ground water level which causes capillary rise of water and an unlined canal is crossing the flexible pavement and damages it. Use of Saline and acrylic co-polymer in waterlogging area to make soil water proof, results in incremental value of CBR under wet condition and reduces these damages as well as stopping the capillary rise of water. minimizing the level of maintenance and increase in overall life span of road are both an added advantage for using these nano materials. and it helps to reduce pavement thickness as well its material so cost reduction is added advantage here (JAY et, al., 2017).

\subsection{Nanomaterials in Asphalt Binders}

All the researches carried out by many scholars and practitioners were to determine the effect of nanomaterial on the asphalt binder. According to research conducted by(Mohd, et. al., 2014) nano silica was added and the optimum value used in asphalt binder ranges from 2-6\% which decreases penetration value, increases the softening point value as well as increase the viscosity. Also,another research conducted by them shows that susceptibility due to moisture decreases upon subjecting the modified bitumen mixtures to moisture sensitivity, resilient modulus and dynamic creep test to both short and long term modified binders, in addition the dispersion of the nano silica was successful as it was tested using SME analysis.

\subsection{NANOMATERIALS FROM AGRICULTURAL WASTE}

Agricultura nanomaterial waste such as palm oil fuel ash (POFA), rice husk ash (RHA) and rattan have been proven to have significant effect on modifying the properties of concrete pavement whereas optimum addition of such nanomaterials increase compressive strength, reduces porosity of rigid pavement(Rajak et. al., 2015).

\subsection{SOIL STABILIZATION USING NANO- MATERIALS}

A study was carried out by (Anwar, 2017) on Kuruvilakam road and trial section along sector 19, Gandhinagar, Gujarat, in which organ silane works well with the combination of cement and makes the soil stiff, so that in low traffic area stabilized gravel road can be constructed, the CBR values increases 1700 times with the combination of cement, organ silane and nano polymer. UCS strength increases with the addition of organic silane. another study conducted by (Subramani and Sridevi, 2016) on soil stabilization using nano nanoclays and nano cement found that Various amount of those nanomaterial's $(0.5 \%$ to $2 \%)$ were added to the soil toincrease in the percentage of each of the nanomaterial's increased the maximum dry density of the soil. The linear shrinkage and plasticity index decreased with increasing amount of nanomaterial's content. The unconfined compressive strength increased as the nanomaterial's content increased up to a certain percentage in the soil.

\subsection{OTHER ASPECT TO BE CONSIDERED}

The abrasion resistance of concrete containing nanoparticles (both nano- $\mathrm{TiO}_{2}$ and nano- $\mathrm{SiO}_{2}$ ) for pavement is experimentally studied (H. Li et al., 2006). The abrasion resistance of concrete containing nano- $\mathrm{TiO}_{2}$ is better than that containing the same amount of nano$\mathrm{SiO}_{2}$. The effectiveness of nano- $\mathrm{TiO}_{2}(\mathrm{NT})$ in enhancing abrasion resistance increases in the order: $5 \% \mathrm{NT}<3 \% \mathrm{NT}$ $<1 \%$ NT (with the decrease on NT content). The flexural fatigue performance of concretes containing nanoparticles is significantly improved and the sensitivity of their fatigue lives to the change of stress is also increased. The concrete containing nano-TiO2 (1 wt.\%) showed the best flexural fatigue performance (better than concrete containing polypropylene fibers), which has been extensively used in paving concrete (H. Li et al., 2007).

\subsection{RISKS ASSOCIATED WITH NANOPARTICLES}

Certainly, almost all nanomaterials have their respective risk associated with them especially upon exposure. But lucky the risk is negligible of materials while uses as roadway material, the only probable risk that may occur is contaminating the water table of the area where nanomaterials were used. A research conducted by united state health department revealed that Titania particle are toxic in nature, therefore proper safety guidance and sensitization on health has be established. Because the 
benefits derived from such discoveries are for human development, otherwise may lead serious problem to habitant exposure to such materials therefore such benefits will not diminish the realistic limitations of such materials.A review by (Lin et al., 2008) states that even though nanoparticles may not be inherently safe, it is premature to state that they are inherently dangerous. This uncertainty is a significant factor influencing the decisions of industry and government leaders, as exhibited in the amended version of the national nano initiative in 2008, intended to strengthen research efforts on the environmental, health and safety issues related to the use of nanotechnology.For such reasons some few principles for safety during the design and implementation of nanomaterial were proposed by (Faruqi, 2015) and listed below:

1. Reduction (evaluate the option to use smaller quantities of nanoparticles in the product while maintaining functionality).

2. Encapsulation (enclose a potential hazardous nanoparticle with a material that is less hazardous).

3. Functionalization (bond molecules to nanoparticles to change the properties that can reduce the hazard potential while preserving the desired product properties).

4. Alternative materials (identify an alternative material that can be used to replace the hazardous nanoparticle).

5. Size, surface, and structure (change the size, surface, or structure to reduce the hazard potential of the nanoparticle while maintaining its functionality).

\subsection{SCALE AND COST PROBLEM OF NANOMATERIALS}

Its globally known that all civil engineering activities such as buildings, dams, retaining walls, embarkments, roads seaports, rails etc. deal with bulk and larger scale of materials. And all such constructions are mainly for public utilization which safety and economic are the priority upon feasibility but unfortunately the nanomaterials are produced and available in mini scale therefore civil engineers should constantly bear and acknowledge the huge impact of little nanomaterial will provide not considering the quantity.Actually all nanomaterials are of relatively high cost this is due to technological means of production and the cost equipment's, but as the trend of modern technology changes with time, the monopoly in the production became less due to other forms of competitivediscoveries for the production processes which may lead to the drastic falling cost of production of such materials. Therefore, for the current situation it is advisable to employ the use of nanomaterials in road construction as well as in concrete where there is need for special and immediate attention to the problem. as most of the conventional means of road construction remain viably feasible and cost effective.(Wynand, 2017).

\subsection{RESEARCH GAP FOR FUTURE}

Considering the recent there are many characteristics of nanotechnology that can be applied to pavements to provide a better performance. However, successful nanotechnology application may need further research before commercialization. Some of the potential future trends are listed below(Faruqi, 2015):

1. Engineered materials using nanotechnology will allow maximum use of locally available materials and avoid unnecessary transport.

2. Design ductile, flexible, breathable, permeable or impermeable concrete properties on demand.

3. Design concrete and asphalt mixes which are resistant to freeze-thaw, corrosion, sulfate, and other environmental attacks.

4. Develop specialty products such as products with blast resistant, conductive properties as well as temperature, moisture, and stress-sensing abilities.

5. Future nanotechnology applications will lead to reduce maintenance costs, increase pavement lifespan, reduce accidents, and increase construction efficiency.

\section{REFERENCES}

[1] International Journal of Innovative Technology and Exploring Engineering (IJITEE) ISSN: 2278-3075, Volume-9 Issue-1, November 2019 on topic " Assessement of Safety Management for Public Construction Sites in Nigeria” by Puneet Jain, Lasmar Garba.

[2] "Determining Mix Proportion For The Marble Slurry Powder Recovered From Marble Slurry Replacing Fine Aggregate Of Concrete Used In Residential Construction Project In Udaipur, India" in International Journal of Engineering Research and Application, www.ijera.com ISSN : 2248-9622, Vol. 7, Issue 10, Part -5) October 2017, pp.30-35 by Puneet Jain.

[3] Puneet Jain. Int. Journal of Engineering Research and Application www.ijera.com ISSN : 2248-9622, Vol. 7, Issue 11, Part -5) November 2017, pp.61-65 on the topic " Partial Replacement of Fine Aggregate with Glass Using DIC Technique with Waste Materials for Investigation of Crack Propagation.

[4] Khitab, Modeling of ionic transport in saturated porous medium (PhD. Thesis, National Institute of Applied Sciences, Toulouse, France, 2005)

[5] A.G. Nasibulin, S.D. Shandakov, L.I. Nasibulina, A. Cwirzen, P.R. Mudimela, K. Habermehl-Cwirzen, D.A. Grishin, Y.V Gavrilov, J.E.M. Malm, U. Tapper, Y. Tian, V. Penttala, M.J. Karppinen and E.I. Kauppinen // New Journal of Physics 11 (2009) 083043.

[6] A.M. Neville, Properties of Concrete (Pearson Education, 2011).

[7] Anwar Khitab and Muhammad Tausif Arshad Nano Construction Materials: Review Rev. Adv. Mater. Sci. 38 (2014) 181-189

[8] Bartos, P., Hughes J.J., et al,(2004), "Nanotechnology in construction", Royal Society of Chemistry, Cambridge, UK, pp 375-376.

[9] Chang, M. Ho, G. Song, Y. Mo and H. Li // Journal of Smart materials and structures 18 (2009) 127001.

[10] Camden, (2007), "Pioneering paving to tackle air pollution", Retrieved from http://www.camden.gov.uk

[11] Darshan A. PatelC.B. Mishra Nano Material for Highway Infrastructure International Conference on Research and Innovations in Science, Engineering Kalpa Publications in Civil Engineering Volume 1, 2017, Pages 321-328

[12] E. Quagliarini, F. Bondioli,G.B.Goffredo, C. Cordoni and P MunafQ // Construction and Building Materials 37 (2012) 51.

[13] E.T. Thostenson, Zhifeng Ren, T-W. Chou Composites Science and Technology 61 (2001) 1899.

[14] Faruqi M.*, Castillo L., Sai J. State-of-the-Art Review of the Applications of Nanotechnology in Pavement Materials Journal 
of Civil Engineering Research 2015, 5(2): 21-27 DOI: $10.5923 /$ j.jce. 20150502.01

[15] G. Ferro, J. Tulliani, S. Musso and F.R. Cassino // Giugno 13 (2011) 49

[16] Hassan, M.M., (2009), "Evaluation of the environmental impacts of titanium dioxide photocatalyst coatings for pavements using life-cycle assessment", In: Proceedings of the 88th Transportation Research Board meeting, Washington D.C.

[17] http://wherefivevalleysmeet.blogspot.com/2012/04/forth-bridgeand nanotechnologypaint.html

[18] J.M. Makar and J.J. Beaudoin, In: Proc. 1st International Symposium on Nanotechnology in Construction (Scotland, 2003), p. 331

[19] JAY PRAJAPATI, JAYESH JUREMALANI, NAZIMALI CHINWALA A Proposal of The Nanotechnology Based Flexible Pavement for Water Logging Area International Journal of Advances in Mechanical and Civil Engineering, ISSN: 2394-2827 Volume-4, Issue-4, Jul.-2017 http://iraj.in

[20] K. Sunada, Y . Kikuchi, K. Hashimoto and A. Fujishima, Environmental Science \& Technology 32 (1998) 726.

[21] K.V. Priya1, V. Vijayashri, M. Sakthi Sree,Road Pavements Improvement by Using Nanotechnology, Nanotechnology for Advancement in Transportation Engineering, International Journal of Science and Research (IJSR) ISSN (Online): 23197064Volume 6 Issue 2, February 2017

[22] Kuennen, T., (2004), "Small science will bring big changes to roads", Better Roads, Vol.74(7).

[23] Li, H., M.-H. Zhang, and J.-P. Ou. Abrasion Resistance of Concrete Containing Nano-Particles for Pavement. Wear 260, 2006, pp. 1262-1266

[24] Lin, K. L., W. C. Chang. D. F. Lin, H. L. Luo, and M. C. Tsai. Effects of Nano-SiO2 and Different Ash Particle Sizes on Sludge Ash-Cement Mortar. Journal of Environmental Management, Vol. 28, No. 6, 2008, pp. 708-714

[25] Liu, R., Zhibin, Z. \& Rui, Z., et al, (2007), "Nanotechnology synthesis study: Research Report", Texas Department of Transportation.

[26] M.S. Dresselhaus, G. Dresselhaus and P. Avouris // Topics Appl. Phys. 80 (2001) 287

[27] M.S. Konsta-Gdoutos, Z.S. Metaxa and S.P. Shah // Cement and Concrete Research 40 (2010) 1052.

[28] Mohd Ibrahim, M.Y., Ramadhansyah, P.J., Mohd Rosli, H., Mohd Haziman, W.I. "An Overview on the Performance of Nano Silica Materials on the Properties of Porous Concrete Pavement." Advanced Review on Scientific Research 1, no. 1 (2014): 34-42.

[29] N. Banthia, In: Proc. FIBCON2012 (ICI, Nagpur, India, 2012).

[30] N.N. Coleman, U. Khan, W.J. Blau and Y. K. -JCZ @D Carbon 44 (2006) 1624

[31] Partl, M.N., (2004), "Nano-science and technology for asphalt pavements", In Special publication-Royal Society of Chemistry, Cambridge, UK, 343-356

[32] Plaisted, T.A., Amirkhizi, A.V., Arbelaez, D., et al, (2003), "Selfhealing structural composites with electromagnetic functionality", Proceedings of the SPIE, doi: 10.1117/12. 483898

[33] R.C. MacPhail, E.A. Grulke and R.A. Yokel // Wiley Interdiscip Rev NanomedNanobiotechnol. 5 (2013) 374

[34] R.L. Jacobsen, T.M. Tritt, J.R. Guth, A.C. Ehrlich and D.J. Gillespie // Carbon 33 (1995) 1217.

[35] Rajak, M.A.A., Abdul Majid, Z., Ismail, M. "Morphological characteristics of hardened cement pastes incorporating nanopalm oil fuel ash." Procedia Manufacturing 2 (2015): 512-518.

[36] S. Anwar Hussain (2016) Soil Stabilization Using Nano-Materials for Rural Roads-A Case Study International Journal of Innovative Research in Science, Engineering and Technology Volume 5, Special Issue 14, December 2016

[37] Soil Stabilization using Nano Materials

[38] Steyn, W., (2009), "Potential applications of nanotechnology in pavement engineering", Journal of Transportation Engineering, Vol. 135(10), pp 764-772.

[39] Transportation Research Board, (2012) "Nanotechnology in concrete materials", Transportation Research Circular E-C170, pp. $4-25$
[40] V. Subramani S. Sridevi Soil Stabilization using Nano MaterialsInternational Journal for Research in Applied Science \& Engineering Technology (IJRASET) Volume 4 Issue III, March 2016

[41] V.C. Li Journal of Advanced Concrete Technology 1 (2003) 215

[42] www.italcementigroup.com

[43] Wynand Jvdm Steyn Potential Applications Of Nanotechnology In Pavement Engineering Journal Of Transportation Engineering (C) Asce / October 2009 / 6

[44] Z. Pan, W. Lee, L. Slutsky, R.A. Clark, N. Pernodet and M.H. Rafailovich // Small 5 (2009) 511. 